\title{
On-farm Rice Straw Burning: Its Prevention and Solution
}

\author{
Sourav Ghosal ${ }^{1}$, Srabani Ghosal ${ }^{2}$, Jyoti Ranjan Rath ${ }^{3}$ and MK Ghosal ${ }^{4}$ \\ ${ }^{1}$ Civil Engineering Researcher, IGET, Sarang, Odisha, India \\ ${ }^{2}$ M.Sc. (Ag) student, Department of Agricultural Extension Education, Orissa \\ University of Agriculture and Technology, Bhubaneswar, Odisha, India \\ ${ }^{3}$ Research Scholar, Department of Agricultural Economics, Visva Bharati University, \\ West Bengal, India \\ ${ }^{4}$ Professor, Department of Farm Machinery and Power, Orissa University of \\ Agriculture and Technology, Buhubaneswar, Odisha, India \\ *Corresponding Author: Manoj Kumar Ghosal, Professor, Department of Farm \\ Machinery and Power, Orissa University of Agriculture and Technology, \\ Buhubaneswar, Odisha, India.
}

Received: November 30, 2020

Published: April 10, 2021

(C) All rights are reserved by MK Ghosal., et al.

\begin{abstract}
On-farm burning of rice straw is at present an increasing concern in India where, rice is cultivated widely and the staple food for almost all people of the country. Rice straw is therefore considered to be a sustainable bio-resource as it is available and generated adequately because of the cultivation of the crop twice in a year in major parts of India. Farmers are forced to use combines to complete the harvesting work of the crop within a short period due to the shortage of labour, unpredicted rainfall and natural disaster frequently occurring during the period of crop harvesting. No other option lies with the farmers but to burn the loose straw, generated after combine harvesting, for preparing their fields ready for performing the sowing operation of the next crop. This practice results into the emission of greenhouse gases, causing adverse effects on the environment and becomes a major concern for the whole country. Hence this paper discusses the suitable technologies for utilization of dumped loose straw in the field, in an environmentally sustainable manner and thus preventing the practice of on-farm burning.
\end{abstract}

Keywords: On-farm Burning of Rice Straw; Biofuel; Bio-ethanol; Lignocellulosic Biomass; Microwave Pyrolysis

\section{Introduction}

The practice of following combine harvesting for rice and wheat crops in almost all states of India is increasing day by day due to labour shortage, high wages during harvesting season, ease of harvesting and threshing and uncertainty of weather. It has been reported that around $80 \%$ of rice residues are accumulated in the field by the use of combine harvester and farmers are compelled to burn the loose straw in situ. As rice straw contains more silica, it is not hygienic as a potential feeding material for the animals and is left in the field without its collection and utilization. For preparing the field ready for sowing of seeds for the next crops in a short period, farmers have no other alternative but to burn the loose straw in the field because of their interference in use of tillage and sowing equipment.
The adverse effects of burning of loose straw are very well known to the environmentalists, farmers and policy makers. Farmers are forced to do the practice of burning of crop residues because of the lack of suitable technology at their hand for proper utilization in a cost effective manner. The increased use of combine harvester is also posing the more problem in making loose straw while harvesting. The convenient and simple approach for the farmers is to burn the loose straw in situ, but the practice causes more air pollution for the environment and results into the adverse effects on the human health. By the way, the soil health deteriorates due to loss of nutrients for the plants and required organic carbon. It is reported that the pollutants released by burning of one ton of plant residue are about 1,515 $\mathrm{kg}$ carbon dioxide, $92 \mathrm{~kg}$ carbon monoxide, $3.83 \mathrm{~kg}$ nitrogen oxide, $0.4 \mathrm{~kg}$ sulphur dioxide, $2.7 \mathrm{~kg}$ 
methane, and $15.7 \mathrm{~kg}$ volatile organic component of non-methane in nature [1]. The gaseous emissions from burning of paddy straw thus comprise of $70 \% \mathrm{CO}_{2}, 7 \% \mathrm{CO}, 0.66 \% \mathrm{CH}_{4}$ and $2.09 \% \mathrm{~N}_{2} \mathrm{O}$ [2]. The direct drilling of seeds for any crop into a combine harvested rice fields having stubbles, poses an adverse situation without prior burning or complete removal of the straw. Therefore, it is high time to adopt suitable measure to tackle the problem of on-burning of crop residues. The practice is now so grave that suitable policy needs to be framed on priority basis for encouraging the various uses of residues in promoting conservation agriculture and to reduce their burning in the field itself. Looking into the degradation in the quality of air, the rampant burning of crop residue at present has become a major issue to solve it. It is now a challenge for the farmers for economic and effective handling of rice straw of about 8-10 t/ha for facilitating the tillage and sowing operation for the next crop within a short period of 15 days. The use of seeding and tillage machinery are hampered due to the presence of loose straw, produced by the combine harvesting. No such machinery is available till date for performing direct sowing operation in the field where combine harvester is used. This constraint needs to be resolved by suitable technologies which would become environmentally sustainable and economically viable for the majority of small and marginal farmers of India.

Use of happy seeder: A viable solution for on-farm crop residue burning

As the practice of burning of crop residue is increasing day by day and is spreading in the major parts of the country, the popularization and promotion of happy seeder may be an appropriate solution. The machine simultaneously cuts the plants, lifts them and sows the seeds on the straw lying in the field and covers the seeds with the loose straw similar to the mulching operation. The use of machine therefore permits the farmers to accomplish the sowing operation just after combine harvesting without adopting the practice of burning the residues for preparation of land. The use of happy seeder is reported to be more cost effective and requiring less time involvement in preparation of land and sowing operation compared to conventional tillage. The farmers need to be aware of the comparative advantages the happy seeder in view of promoting conservation agriculture as against conventional tillage. The happy seeder saves both time and cost in preparation of land and sowing of the seeds for the next crop. Farmers need not face the difficulty of clearing the land from the loose rice straw and thus be away from burning them in the field. It is also cheaper compared to conventional tillage and sowing operations. It has been reported that an amount of Rs. 1800-2000 per hectare on average can be saved compared to the using conventional practice. It has also been stated that the yield of the wheat crop by using happy seeder is at par with the practice following with the conventional method.

\section{Bio-ethanol from rice straw}

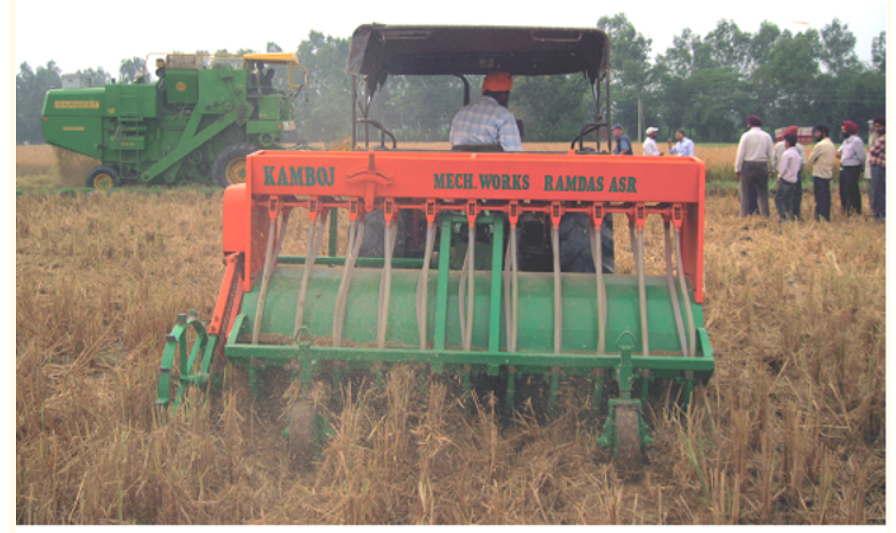

\section{Happy seeder|}

Figure a

Agro-residues are generally available plentifully in an agricultural based country like India. The solid residues can be converted into the liquid biofuel for easy handling, transportation and trading. However, pre-treatment is necessary for delignification of these lignocellulosic biomass. Rice straw being a lignocellulosic biomasses has the potential to produce bio-ethanol after following proper technique. Its characteristics support to produce the ethanol for fuel purpose. For ethanol production, the biomass needs to be converted into the fermentable sugar. The higher content of hemicellulose and cellulose can be hydrolysed readily into the sugar for ethanol preparation. Looking into its chemical composition, the percentages in the content of cellulose, hemicellulose and lignin in straw are respectively (32-47\%), (19-27\%) and (5-24\%). The hemicellulose contains the pentoses which produce xylose, an 
important sugar component (14.8-20.2\%). It is reported that the amount of cellulose in $1 \mathrm{~kg}$ rice is about $390 \mathrm{~g}$. It has been experimentally found that $390 \mathrm{~g}$ of cellulose can produce the ethanol of around $220 \mathrm{~g}$ or $283 \mathrm{ml}$ [3].

\section{Pre-treatment}

Rice straw can be considered as a potential lignocellulosic material for producing bioethanol because of its abundant availability and renewability in nature. However, more content of ash and silica makes it unfavourable for preparation of ethanol. Hence, the pre-treatment is an important aspect while selecting rice straw for producing ethanol in order to enhance the efficiency of enzymatic saccharification and thus making the process cost effective. Two processes are generally encountered in the process of preparation ethanol, i.e. one for converting carbohydrate to the fermentable sugar through hydrolysis and the second one is to ferment the sugar to ethanol by the process of fermentation. The process of hydrolysis is accelerated by the enzyme i.e. cellulose and fermentation by bacteria or yeast. The entry of the enzyme cellulose into the feedstock is difficult due to the presence of hemicellulose and lignin in the lignocellulosic biomass and hence the process of hydrolysis gets reduced. However, this problem can be solved by following proper pre-treatment before starting the hydrolysis process. Pre-treatment removes hemicellulose and lignin and reduces the crystallinity of cellulose and increase porosity. The pre-treatment process is generally divided into three segments, i.e. physical, chemical and biological. The physical process accomplishes mechanical action for chipping, grinding and proper milling in order to reduce the crystallinity of cellulose and to alter the physical characteristics of the feedstock. In chemical process, acids or alkali are used to reduce the cellulose, hemicellulose and lignin to a form of fermentable sugar. Acids helps in the process of hydrolysing hemicellulose and alkali is for lignin component [4]. In biological process, various micro-organisms such as fungi and brown are used to degrade lignin and to solubilize the hemicellulose [5]. Hence, proper hydrolysis such as chemical and enzymatic hydrolysis and fermentation process needs to be followed [6] and to be made aware among the users for preparing ethanol from the rice straw. There by the practice of on-farm burning can be reduced to a great extent. The farmers may also get an opportunity to earn their livelihood by trading the ethanol in local nearby markets.

\section{Production of biofuels through microwave assisted pyrolysis}

Comparing to the conventional pyrolysis (CP), the microwave pyrolysis is now gaining momentum due to saving of energy, time and maintaining increased heating efficiency, accurate control during the process and improvement in the yield of the products, desired for the purpose $[7,8]$. In CP, the heat energy is transferred from outside to the feedstock inside the reactor through convection, conduction and then by radiation causing its losses in the process of transference. However, in Microwave Assisted Pyrolysis (MAP), the feedstock receives the microwave radiation and absorbs it directly, without being lost in any form such as in conduction and convection during its transference from the source to the reactor which is transparent to it [9]. The frequencies of microwave generally range from $300 \mathrm{MHZ}$ (wavelength 1) to $300 \mathrm{GHZ}$ (wavelength $1 \mathrm{~mm}$ ) [10]. The heating mechanism in MAP is therefore, a type of energy conversion rather than transfer of heat. The secondary reactions which are not required during the pyrolysis process are controlled and can be prevented by maintaining the uniformity and effective control of the temperatures inside the reactor. By the way, the desired outputs can be produced. Higher heating rates can also be accomplished due to the transfer of energy at molecular and atomic level within the material [11]. It has been reported that the biomass feedstock is poor in the absorption of microwave because of its low dielectric properties [12], hence, it is necessary to add the microwave absorber materials for increasing the heating efficiency and higher yield of the pyrolytic products. This problem can possibly be solved by adding the biochar produced from the same pyrolyzer and thus involvement of additional cost for the process can be reduced. The pyrolysis process can also be undertaken with the help of a reliable power source i.e. solar PV electricity, for its easy acceptance in the rural areas where the availability of conventional electricity is most erratic and irregular. The production of more useful and value added products from rice straw (Figure 1) in a convenient and sustainable manner by following microwave assisted pyrolysis with the reliable solar PV electricity would become sustainable for its safe disposal, mitigating greenhouse gas emissions by preventing improper uses and creating avenues for earning livelihood particularly among resource poor rice growers. 


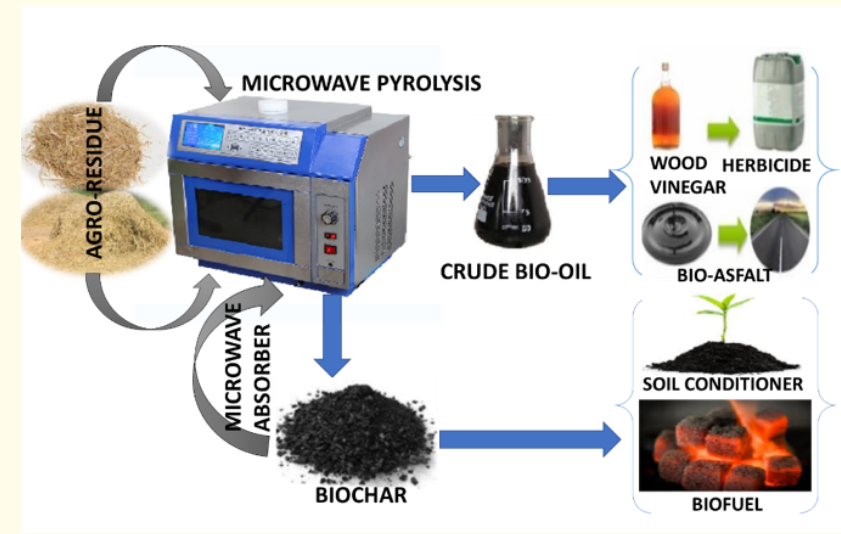

Figure 1: Pyrolysis products from microwave pyrolysis of agro-residue.

\section{Conclusion}

For effective utilization of the most neglected agro-residue i.e. rice straw, it is highly necessary for adopting the sustainable practice of MAP for converting them into value added biofuels. Rice straw may be used as a potential biomass feed stock for producing bioethanol and value added pyrolytic products i.e. bio-oil, syngas and biochar. Proper utilization of this dumped agro-residue would enhance the livelihood of the users and improves the environment sustainably. Looking into the growing concern of rampant burning of on-farm rice straw, it is high time to evolve the technologically feasible, economically viable and environmentally sustainable practices to solve this problem. The practices discussed in this article would definitely produce a new dimension not only for the environmentalists but also the planners, policy makers and farmers. The value added biofuels would enhance the livelihood of the farmers in addition to the proper utilization of the other crop residues in sustainable manner and preventing their on-farm burning.

\section{Bibliography}

1. Jain Niveta., et al. "Emission of Air Pollutants from Crop Residue Burning in India". Aerosol and Air Quality Research 14 (2014): 422-430.

2. Sidhu Ruby., et al. "Impact of Stubble Burning on the Ambient Air Quality". International Journal of Mechanical and Production Engineering 3.10 (2015).

3. Belal EB. "Bioethanol production from rice straw residues". Brazilian Journal of Microbiology 44 (2013): 225-234.

4. Demirbas A. "Bioethanol from cellulosic materials: a renewable motor fuel from biomass". Energy Sources 27 (2005): 327333.

5. Sarkar Nibedita., et al. "Bioethanol production from agricultural wastes: An overview”. Renewable Energy 37 (2012): 19-27.

6. Demirbas A. "Products from lignocellulosic materials via degradation processes”. Energy Source A 30 (2008): 27-37.

7. Chen P., et al. "Utilization of municipal solid and liquid wastes for bioenergy and bioproducts production". Bioresource Technology 215 (2016): 163-172.

8. Du Z., et al." Microwave assisted pyrolysis of microalgae for biofuel production". Bioresource Technology 102 (2011): 4890-4896.

9. Menéndez JA., et al. "Microwave heating processes involving carbon materials". Fuel Processing Technology 91 (2010): 1-8.

10. Haque KE. "Microwave energy for mineral treatment processes- a brief review". International Journal of Mineral Processing 57 (1999): 1-24.

11. Saifuddin Nomanbhay., et al. "Microwave pyrolysis of lignocellulosic biomass--a contribution to power Africa". Energy, Sustainability and Society 7 (2017): 23. 
12. N Ferrera-Lorenzo., et al. "Conventional and microwave pyrolysis of a macroalgae waste from the Agar-Agar industry. Prospects for bio-fuel production". Bioresource Technology 151 (2014): 199-206.

\section{Assets from publication with us}

- Prompt Acknowledgement after receiving the article

- Thorough Double blinded peer review

- Rapid Publication

- Issue of Publication Certificate

- High visibility of your Published work

Website: www.actascientific.com/

Submit Article: www.actascientific.com/submission.php

Email us: editor@actascientific.com

Contact us: +919182824667 